\title{
Why do we need perceptual content?
}

\author{
Ayoob Shahmoradi iD \\ Department of Philosophy, University of Sydney, Sydney, Australia
}

\begin{abstract}
Most representationalists argue that perceptual experience has to be representational because phenomenal looks are, by themselves, representational. Charles Travis (2004) argues that looks cannot represent. I argue that perceptual experience has to be representational due to the way the visual system works.
\end{abstract}

\author{
ARTICLE HISTORY \\ Received 20 November \\ 2014 Revised 3 June 2015 \\ Accepted 15 August 2015 \\ KEYWORDS \\ Bayesian theories of perception; \\ empirical ranking theory; \\ inverse problem of vision; \\ looks; naïve realism; perceptual \\ content; representationalism
}

\section{Introduction}

Representationalism has been a prominent, if not the prominent, view regarding the nature of mental states for the last two decades. According to representationalism, phenomenal properties are identical to (or supervene on) representational properties (Chalmers, 2004; Dretske, 1995; Tye, 1995, 2002). So it is not very surprising that most of the challenges that representationalism has faced are weird cases in which it is argued that phenomenal character and representational content, in certain circumstances, could come apart. Although these cases pose serious threats to specific versions of representationalism, they do not undermine the fundamental insight behind representationalism in general: the idea that perceptual experience necessarily possesses representational content. Call this the Strong Content View. Note that although representationalism entails the Strong Content View, the latter does not entail the former. The Strong Content View is a weaker thesis in that it is silent on the relation between representational properties and phenomenal properties.

Many people have taken the Strong Content View for granted or as intuitively obvious. David Chalmers believes it is "intuitively very clear that perceptual phenomenology, by its very nature [emphasis added], involves the representation of the external world" (2004, p. 157). Others have assumed that the very idea of phenomenology is sufficient to show that perceptual experience is representational. Alex Byrne claims that the content thesis "should be no more controversial than the notion that a subject's belief state represents the world" (2001, p. 201). Susanna Schellenberg argues that "the mere fact that the world seems a certain way [emphasis added] when one perceives entails [emphasis added] that the perception has content" (2011, p. 722). And Terry Horgan and John Tienson suggest that "there is a kind of intentionality, pervasive in human mental life, that is constitutively determined by phenomenology alone [emphasis added]" (2002, p. 520).

Despite its initial plausibility, Charles Travis (2004) has recently launched an attack on the Strong Content View. The idea behind Travis' main argument is that phenomenology cannot uniquely determine representational content, and hence that perceptual experience could not be representational. 
Travis further argues that, contrary to Brentano and his followers, the mental is not essentially representational (intentional). In other words, representation is always derivative in the sense that something/someone takes something to represent thus and so.

In this paper, I will focus on Travis' argument from indeterminacy of representational content and argue that although Travis' argument could plausibly show that, contra the representationalists I mentioned above, looks are not by themselves representational, it does not affect a weaker view-that perceptual experience has to be representational due to the way the visual system works. Call this the Weak Content View (or the WCV for short). ${ }^{1}$

\section{Travis' argument}

Unfortunately, Travis' writings are not very accessible. As a result, people have reconstructed his argument in different ways. But I believe that the following formulation is a charitable reading of Travis' position. ${ }^{2}$

Let's begin with a background on different uses of 'look' (and other appearance words like 'seem' and 'appear'). Following Chisholm (1957), we may identify three uses of the word. One rather uncontroversial use is the comparative use. When I say that "John looks like his older brother," Chisholm would say that I have used 'look' in a comparative sense. Another use of the term, the epistemic use, occurs when I use 'look' to report the content of an inference. For instance, suppose that I hear on the radio that bus drivers are on strike today, and I tell my friend that "It looks (/seems) as if you have to drive me to school today." Chisholm recognizes a third use of 'looks' whose contents are purportedly grounded in the phenomenology of perceptual experience. For instance, when I say "This car looks red" based on my visual experience of the car, the word 'looks' has been used to report the content of my visual experience. He calls this use of the term the phenomenal use.

Travis denies the existence of this last category. In particular, he argues that if perceptual experiences have contents, their contents should be uniquely expressible in terms of look statements. ${ }^{3}$ Then he tries to show that looks could not fix the content of perceptual states. Given that representationalists (roughly) argue that perceptual experience has content $p$ when it (phenomenally) looks to $\mathrm{S}$ that $p$, it should not be implausible to claim that if perceptual states represent, their contents need to be given by looks (or look statements) (Chalmers, 2004; Siegel, 2010; Siewert, 1999). ${ }^{4}$ Even externalists about mental content have to agree, otherwise it is not clear how the subject finds out what her perceptual states represent. However, Travis argues that looks (or, alternatively, look statements) could not fix the content of perceptual states. In other words, he denies that there is a phenomenal use of the word which fixes the content of one's perceptual experiences. He acknowledges only two uses of the word 'look'.

One use, which corresponds to Chisholm's comparative use, is when someone says, for instance, "Pia looks like her sister" or "That ball looks like a tomato." This use of 'look' does not fix a specific content. For instance, Pia could look like her sister in many different ways, or an object could look like a tomato with respect to, for instance, its color or shape. Thus, this use of 'look' is not an appropriate candidate for giving the representational content of perceptual states.

Travis recognizes another use of 'look', corresponding to Chisholm's epistemic use, which has determinate contents. However, its contents are not fixed only by visual phenomenology; rather, they are fixed given one's beliefs and other epistemic states (Travis, 2004, p. 77). For instance, the way a tomato in daylight looks could represent that the tomato is red. However, Travis argues that the content of the look in such a case is determined, at least partially, by other things, including one's beliefs and other epistemic attitudes. To put it another way, phenomenology alone could not fix the content of one's experience. Thus, there is no separate category of looks which have fixed contents solely in virtue of the way things phenomenally look. ${ }^{5}$ 
Here is Travis' argument from indeterminacy of phenomenology:

1. If perceptual experiences represent, their content has to be determinate.

2. Perceptual content is determined by looks.

3. Looks, by themselves, do not have determinate contents.

4. Therefore, perceptual experiences do not represent.

The first premise of this argument does not seem to be controversial among representationalists. As I mentioned above, most representationalists accept (2) as well. Given (1) and (2), if perceptual experience represents, its content needs to be determined merely by a look. However:

A peccary, confronted in the right way, may look exactly like a pig. ... It may also look like a tapir, a clever dummy pig, a wax imitation peccary, and so on. Experience cannot coherently represent it to us as both a peccary and wax (and a pig, and so on). (Travis, 2004, p. 73)

Therefore, according to Travis looks by themselves do not deliver determinate contents. However, if experience represents at all, it has to represent all these scenarios. But, since the representational content cannot coherently consist of all these scenarios, experience is not representational.

\section{Content comes back}

In the rest of this paper I will argue that Travis' argument fails. I begin by looking at Travis' account of error. Then, after a short review of some other naïve realist solutions to the problem of perceptual error, I build up a schematic argument which is intended to put forward a schema, rather than a single argument, for a defense of the WCV. Thus, in the first step, I argue that naïve realist explanations of perceptual error are problematic. Yet these cases could be easily handled given a representational account. In the next step, I argue that Travis' argument, though very insightful, does not show that perceptual experience is not representational. Finally, I will put forward a positive argument according to which only if perceptual experience is representational can we account for how we can enjoy fine-grained and highly determinate phenomenal experiences from highly underdetermined stimuli.

Two points are in order. First, my argument is, again, a schematic defense of visual content. That is, even if one thinks that naïve realists could have other explanations of perceptual error in their repertoire, the opponent could replace the first step of the argument with similar criticisms of the alternative explanations. Second, my arguments should be understood as a defense of the Weak Content View rather than representationalism. I only show that perceptual experience has to be representational, and this is not the same as saying that the representational content exhausts phenomenal character, or even that phenomenal character is intrinsically representational.

\subsection{Perceptual error as erroneous judgment}

By denying that perceptual experience has representational content, Travis suggests that perception should be understood as a direct (i.e., unmediated) relation between perceivers and their surroundings. Thus, perception could not relate you to non-existent objects and properties. However, according to the content theorist, we sometimes seem to experience things not as they really are. A stick that is half immersed in water may look as if it is bent when it is not really bent; or while driving on a hot sunny day, you may seem to see a shimmering puddle of water on the road where there is no water. Given that Travis takes perception to be a metaphysically unmediated relation between perceivers and their surroundings, he needs to offer an account of these abnormal cases and of perceptual errors more generally in cases in which there is nothing there for the perceiver to be related to. In what follows, I discuss Travis' explanation of perceptual errors.

Consider an optical illusion like the one in figure 1, which is known as the Kanizsa Triangle Illusion. People normally report that they see a white equilateral triangle in this picture. However, precisely speaking, there is no triangle in this picture. 


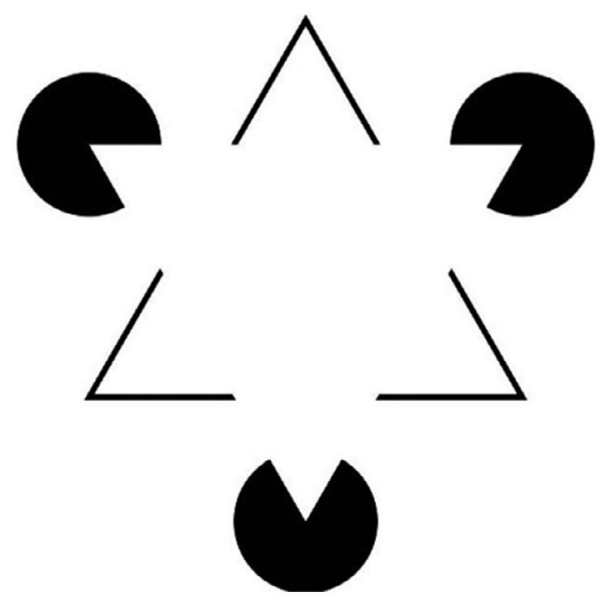

Figure 1 Kanizsa triangle. Many people see a white equilateral triangle in this image while, strictly speaking, there is no triangle there.

Optical illusions such as this one pose a threat to Travis' view about the nature of perceptual experience. According to Travis' relationalist account of perception,

perception simply places our surrounding in view; it confronts us with what is there. ... It makes us aware, to some extent, of things (around us) being as they are... Perception cannot present things as being other than they are. It cannot present some way things are not as what is so. That would not be mere confrontation. So it cannot represent anything as so. Representation, by nature, is liable to be of what is not so. (2004, p. 65)

Travis' explanation requires something to be there to be perceived; awareness needs to be awareness of something. Or as he puts it, perception cannot (re)present things the way they are not because perception is mere confrontation with what is there. By contrast, in order to represent $O$, it is not necessary for $O$ to be present or even exist. The representationalist could say that although there is no triangle in the Kanizsa Triangle Illusion, one's experience represents (or rather, misrepresents) a white triangle in the middle of the picture. The explanation is simple: representation by its nature "is liable to be of what is not so." Therefore, it seems that the case of optical illusions fits well with the representationalist account of perceptual experience.

Nevertheless, matters are not so simple. Travis has an explanation of perceptual error which at the same time is a potential objection to my account of the Kanizsa Triangle. He argues that, in such cases, we fail to take what we confront for what it is. As he puts it, "perception leads me astray only where I judge erroneously, failing to make out what I confront for what it is" (Travis, 2004, p. 65). In other words, error happens at a cognitive level, where I make a judgment, not at the level of perceptual experience, where I am merely confronted with the world as it is.

Travis' use of the role of judgment in perceptual error could be understood in different ways. One way to understand it is to take perceptual error to be due to one's voluntary judgments, where by a "voluntary judgment" I mean a judgment over which one has voluntary control. The judgment that $p$ is a voluntary judgment when one can judge that $p$, or withhold judgment that $p$, or judge that $\sim p$. If this is what Travis means by erroneous judgment, then in any case of perceptual error, one must be able to change one's judgments and thus get rid of the error. So, for instance, if my illusive experience in the Kanizsa Triangle is due to an erroneous judgment over which I have voluntary control, I must in principle be able to withhold that judgment (and thus change the way things look to me), which seems absurd (see Pylylshyn, 1999).

Another way to understand Travis is to attribute perceptual errors to judgments which are automatically produced along with certain perceptual states. This interpretation needs to be accompanied by an appropriate account of cognitive phenomenology and an account of how one is led to mistake a judgment for a perceptual experience; also, one needs to explain how it is that these judgments are 


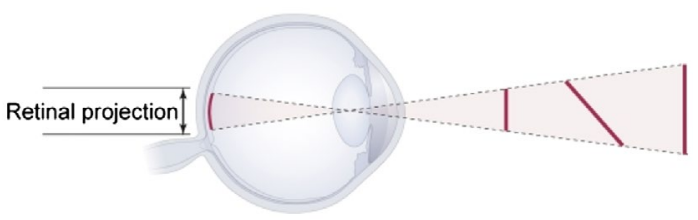

Figure 2 The retinal image is underdetermined with respect to size, distance, and orientation of the perceived objects. (From Purves, Wojtach, \& Lotto, 2011 with permission)

produced only in certain cases and not in others. In other words, how does one's cognitive systems decide to produce such a judgment whenever one is looking at the Müller-Lyer lines and not when one looks at an apple?

Nevertheless, a deeper problem for any cognitive account of perceptual error, in general, comes from perceptual psychology. We know that the retinal image is in some crucial ways underdeterminate and highly impoverished. First of all, the retinal image is two-dimensional, whereas we enjoy three-dimensional visual experiences (Palmer, 1999, p. 23). Second, the stimulus that reaches one's retina is infinitely indeterminate with respect to different objects' luminance properties (Gilchrist et al., 1999). Therefore, the retinal image is indeterminate at least with respect to the depth, orientation, and luminance properties of objects. Thus, in principle, the retinal image could be mapped into an infinite number of different three-dimensional scenes with infinitely many different luminance properties (figure 2).

How does the visual system solve the problem? Well, there is no straightforward way to pick out the corresponding scene. Nevertheless, thanks to perceptual psychology, we know that the visual system avoids these underdetermination problems by "making a lot of highly plausible assumptions about the nature of the environment and the conditions under which it is viewed" (Palmer, 1999, p. 23). What these assumptions (or "heuristics," as Palmer puts it) exactly are and what they are supposed to do is a matter of debate (I will come back to this issue in section 3.4). However, what is important for my present purpose is that this process of relying on assumptions is not infallible after all: sometimes the visual system relies on wrong assumptions, resulting in visual error. In such cases, the error happens to cause a mismatch between one's (reconstructed) visual experience and the external scene. ${ }^{6}$ The visual system makes unconscious assumptions about different aspects of the perceived scene. Sometimes these assumptions are not accurate, and thus the resulting experience does not accurately present (/represent) the way the perceived scene really is.

According to most theories in perceptual psychology, at least some cases of perceptual error are due to inaccurate assumptions of the perceptual system, in the above sense, over which the subject has no control: In order to disambiguate the retinal stimulus, the visual system needs to rely on some further assumptions. For instance, the visual system normally assumes that light comes from above. Or, it relies on texture gradient, that is the changing size of the elements of a picture, as in the square elements in figure 3 , as a cue to the depth of the perceived scene. The retinal image accompanied with the unconscious assumptions of the visual system forms one's visual experience. Therefore, the inaccurate assumptions affect the experience itself. The visual system crucially needs these assumptions in order to disambiguate the retinal image. If they are erroneous in a certain case, then the resulting experience itself will be erroneous. If, on the other hand, they are accurate, the resulting experience will be veridical. Thus, the formation of perceptual experience in general depends on these assumptions. Regardless of what the nature of these assumptions is, and regardless of whether they are representational or not, the visual system has to rely on them to turn the underdetermined retinal image into a determinate conscious experience.

If this account of the visual system is plausible, it shows that at least some cases of error are experiential. Accepting that perceptual error is experiential is not compatible with metaphysical direct realism 


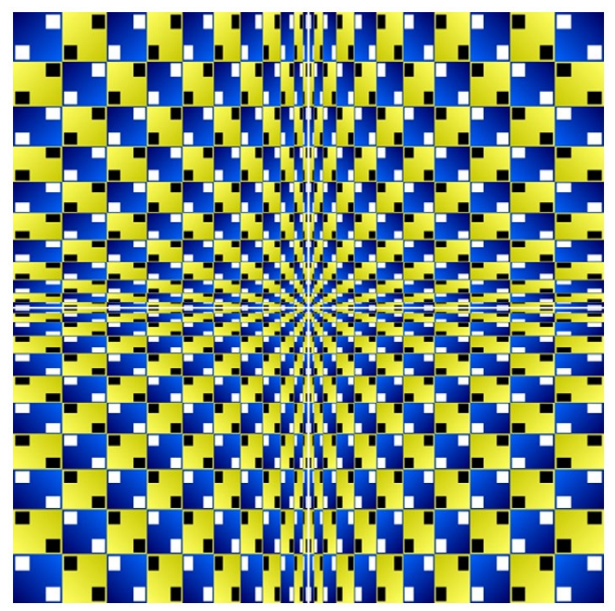

Figure 3 "Valley" (By Akiyoshi Kitaoka with permission). The visual system relies on texture gradient as a clue to the depth of the perceived scene.

according to which "perception cannot present things as being other than they are. It cannot present some way things are not as what is so. That would not be mere confrontation" (Travis, 2004, p. 65).

The naïve realist could still offer more complicated accounts of error. For instance, one might think that perceptual error could be due to unconscious judgments which occur after the perceptual experience is formed and affect one's beliefs about the experience. I do not need to rule out this or other more complicated accounts of perceptual error. However, as I explained above, according to our best theories in perceptual psychology, experience itself could be erroneous. Plus, again, these more complicated accounts of perceptual error need to be accompanied with appropriate accounts of cognitive phenomenology, as well as an error theory which tells us how it is that one tends to mistake the content of the alleged mistaken judgments with one's experience. ${ }^{7}$

Before I move on, I need to highlight few points. First, the psychological explanation of error given above is part of a more comprehensive paradigm in perceptual psychology which provides explanations for a variety of phenomena, including normal perceptual experience of depth, luminance, orientation, different sorts of constancies, and binocular rivalry. Therefore, it is not a single ad hoc explanation offered specifically for error. Second, the possibility of error in perceptual experience is not a problem merely for the naïve realist accounts of error. Rather, it is a threat for naïve realism itself according to which in perceptual experience we are merely confronted with what is out there. Thus it is not clear how, for instance, illusive appearance of depth creeps into this unmediated confrontation relation when one looks at figure 3 (see Shahmoradi, 2015a). Third, one might be tempted to argue that the unconscious assumptions that the visual system employs are representational and conclude that perceptual experience is, too. I do not find this a plausible line of argument for familiar reasons. For instance, it is not very clear how these subpersonal representations could be used to explain personal-level phenomena. Moreover, some people have argued that it might be possible to give an alternative account of these sub-personal representations in terms of constraints or biases of the perceptual system (Orlandi, 2014).

\subsection{Naïve realism and perceptual error}

I considered Travis' account of perceptual error and showed that it is not after all a plausible account of error. I also argued that some cases of perceptual error are experiential. However, the naïve realist could argue that Travis' explanation of perceptual error is not the only game in town. So let's take a quick look at some other possible strategies that are available to the naïve realist. 
It is quite well known that naïve realism has a hard time dealing with perceptual error: if an awareness relation to things as they really are constitutes our veridical experiences, as the naïve realist claims, how is it that we sometimes experience things as they are not?

Some naïve realists might want to extend their treatment of hallucination to the case of illusions. In order to do so, they could provide either a positive account of error or an account of error in negative terms. As a positive account, for instance, one could explain the bad cases by appealing to non-physical objects and properties (e.g., sense data) or provide some other, more complicated theories. Mark Johnston, for instance, argues that while in veridical perception

we are aware of instantiations of sensible profiles.... When we hallucinate, on the other hand, we are only aware of the structured qualitative parts of such sensible profiles. Any case of hallucination is thus a case of 'direct' visual awareness of less than one would be 'directly' aware of in the cases of seeing. ${ }^{8}$ (Johnston, 2004, pp. 135-137)

No matter how the naïve realist tries to give a positive account of non-veridical perception, they all face what is known as the screening-off problem (Martin, 2004).

The problem basically is this: suppose in the bad cases of perceptual experience what one seems to perceive is what we might call a mere profile. It seems that certain brain activities are sufficient for the subject to have a hallucination of some mere profile, no matter whether such a profile is being instantiated somewhere in the world or not. If this is right, then we may wonder whether the same kind of brain activities in the good cases of perception is sufficient for having the experience of the same kind of profile too. Let's suppose that, in the good case, these brain activities are sufficient for having the experience of the same kind of profile. Then it is not clear whether we have or need anything over and above the mere profile in the good case. Thus, it seems that the mere profile screens off the object-involving phenomenal character from explaining why the character of the experience is what it is.

Nevertheless, the naïve realist's response to the question might be negative: that is, that brain activities are not sufficient for the subject to have an experience of the same kind of profile in the good case. Now the naïve realist owes us an explanation of why the same brain activity is sometimes sufficient for having an experience and sometimes not. While the former path pushes the naïve realist toward sense-data theory, the latter renders the nature of perceptual experience mysterious, as if the brain has a fancy power to distinguish between when a perceptual state is being produced by an awareness relation to external objects and when it is not. Therefore, the naïve realist's attempt for a positive account of perceptual error does not seem to be very promising.

This has forced some naïve realists to characterize perceptual error in negative terms. Here is the way M. G. F. Martin characterizes hallucination in a naïve realist framework: a hallucination of an object $O$ is such that it is not possible to know through reflection that it is not a veridical perception of an $O$ (2006, p. 364). This is a delicate proposal and has several advantages over positive accounts. Putting these issues aside, however, the negative characterization is not flawless either (see Fish, 2010, p. 102; see also Siegel, 2004). To mention only one, it seems that the "through reflection" condition should be strong enough to prevent one from knowing (through reflection) that one is hallucinating. Thus, for example, it should rule out, for instance, one's background beliefs so that there is no way for the subject to figure out whether or not she is hallucinating. At the same time, in order for the subject to not know through reflection that her experience is a hallucination rather than a veridical perception, she has to have access to her background beliefs about similar cases of veridical perception. As a matter of fact, this is a dilemma which Martin's proposal faces, and there is no easy way out of it (Sturgeon, 2006). Though a difficult problem, this is only one of the challenges that Martin's characterization faces. Although Martin's account is not the only negative account of perceptual error in the literature, other available strategies are not promising either. ${ }^{9}$

Given the above discussion, it should be clear that perceptual error is a serious challenge for the naïve realist. Nevertheless, let's consider another relatively recent defense of a cognitive account of error which could be regarded as a more plausible interpretation of Travis' proposal (Genone, 2014). Recently, some naïve realists have suggested that illusions should be taken to be perceptual, that is, 
as perceptual experiences which the subject has of objective appearances. According to this account, (illusive) appearances are objective properties of objects, and thus nothing abnormal happens when one is having an experience of, say, a straight stick in water which looks as if it is bent, except that one might erroneously judge that it is bent. If this is right, then no error occurs at the perceptual level. The way the stick looks is an objective fact that could be accounted for given facts about the stick, water, and light refraction.

At least prima facie, it is plausible that some appearances are objective properties of objects. However, it is doubtful that this could be extended to all cases of illusions. As I argued above, at least some cases of perceptual error occur due to the underdeterminacy of the stimuli and the fact that the visual system has to rely on further assumptions to make up for what has been lost in the retinal image. As Snowden, Thompson, and Troscianko put it, "our visual system can, and frequently does, get it wrong. It does not represent the physical world correctly because it makes assumptions about the world and uses these to give us the information we need" $(2012$, p. 8).

Here is one example. In figure 3, the center of the figure looks as if it is disappearing into the distance, which gives it a three-dimensional look. However, as a matter of fact, it is a two-dimensional figure, and all the lines are straight. The textbook explanation for the illusive look of depth in this case is that since the retinal image is two-dimensional, the visual system has to rely on further assumptions to reconstruct the depth. During the course of its evolution, our visual system has learned that texture gradient is a cue to the depth of a scene. Although in many cases texture gradient gives a good cue to the depth of the perceived scenes, and thus helps us have accurate perceptions of depth, sometimes the visual system is fooled by the assumption in question, as we see in the figure 3 .

Another well-known assumption of this kind is what is known as the light-from-above assumption (Kleffner \& Ramachandran, 1992). The idea is that since most light in our environment, including the light coming from the sun and most other light sources, comes from above, the visual system has evolved to form such an assumption which is responsible for some optical illusions as well as some accurate cases of depth perception. These assumptions have enabled the visual system to track objective features of the environment which are not directly available to the visual system and thus have helped the organism to interact with its environment in an efficient way. However, that does not mean that these assumptions are being employed in an infallible way. Figure 3 is obviously a two-dimensional figure and cannot have depth as one of its objective features. Therefore, I conclude that there are cases of error which are experiential and due to the structure of the visual system, rather than being perceptual experiences of objective appearances.

Of course, these are not the only possible proposals that a naive realist could in principle come up with, and I am not suggesting that the path to a better solution is logically blocked. However, in the absence of a better proposal, and given the fact that Travis' anti-content argument does not rule out the Weak Content View, there is no reason to balk at an account of perceptual experience according to which perceptual experiences are representational.

\subsection{What is in a look?}

Now, let's go back to Travis' argument from indeterminacy of looks. I admit that, in principle, it is possible that (phenomenal) looks do not determine representational content by themselves. In other words, a certain (phenomenal) look could in principle represent more than one state of affairs. However, this insight does not lead to Travis' anti-content thesis.

Travis' argument teaches us that looks are not representational independently from one's higher-order epistemic states. This insight blocks a very common line of argument that goes directly from looks to their being representational. Having said that, Travis could reject a widely held view shared by, among others, Chalmers (2004), Schellenberg (2014), and Siewert (1999), who move from (phenomenal) looks to their having accuracy conditions and representational content. The basic idea behind these arguments is that: 
Visual experiences are assessable for accuracy in virtue of their phenomenal character. ... [Thus] it would be accurate if and only if there is an object with an appropriate shape in front of the subject. If this is right, then a phenomenal property entails a pure representational property (roughly, representing that there is an object with a certain shape in the world). (Chalmers, 2004, p. 158)

Travis, however, tells us that phenomenology simpliciter fails to give accuracy conditions in the sense we are concerned with, and thus that the above argument is implausible. ${ }^{10}$

Now given that looks need not be representational, proponents of the Weak Content View need to do two things. First of all, they need to argue for why one should take perceptual experience to be representational in the first place. Since, I believe, there is no direct argument from how things look in visual experience to its having content, I suggest that we need to rely on the explanatory role of perceptual content. The idea is that our best theories of vision tell us that, in order to enjoy the visual experiences that we have, the visual system has to turn the retinal image into a representation of the perceived scene, given some further assumptions about the environment and the viewing conditions. ${ }^{11}$ These assumptions enable the visual system to reconstruct visual representations out of highly impoverished and indeterminate inputs. As I will explain in the next section, this could not be accounted for given a perceptual relation between the perceiver and the perceived object and properties. Second, one needs to show how the kind of content defended in the first step could be compatible with anti-content arguments, like that of Travis. The suggestion is that we should reject the widely held assumption that visual content is determined by looks (premise 2 of Travis' argument) (Pautz, 2009). In other words, I agree with Travis that looks, by themselves, do not deliver determinate contents. This is perfectly compatible with visual experience's being representational for other reasons. In particular, I argue that our visual experience is representational due to the structure of the visual system.

\subsection{Why do we need perceptual content?}

It used to be the bedrock of traditional perceptual psychology that the function of the perceptual system in general, and the visual system in particular, is to give the perceiving organism a veridical experience of its surroundings. This seems to be a pretty plausible assumption. Many have assumed that perceptual experience could not be evolutionarily useful unless it provides the organism with a veridical experience of how the world is. According to this view, a normally working visual system is like a transparent glass. It does not interfere with the way the other side of the glass looks to the observer, and it only has a minimal causal role (Geisler \& Diehl, 2003; Palmer, 1999, p. 6; see also Campbell, 2002, p. 116; Fish, 2009, p. 137). However, recently perceptual psychologists have questioned this assumption. They argue that it is not clear why the visual system needs to provide the organism with a veridical experience of its surroundings. Rather, the visual system, first and foremost, needs to facilitate the organism's interaction with its environment and enhance its fitness. This could be done with less than veridical experience (Howe, Lotto, \& Purves, 2006; Purves, Wojtach, \& Lotto, 2011; Singh \& Hoffman, 2013).

Here is how the visual system, according to this view, works. The stimulus that the visual system receives is highly underdetermined. The visual system initially has no way to get around the problem, so it relies on these highly underdetermined inputs to help the organism move around and interact with its environment. Then, "using feedback from the outcome of visually guided behavior in the past," (Perves et al. 2002) the visual system modifies the organism's perceptual experiences. According to this view, the ultimate goal of the visual system is to enable the organism to behave successfully in its environment. However, many people tend to assume that the output of a visual system evolved in this way finally converges toward another visual system that is tuned to veridicality. If so, then the best way for the visual system to enhance the organism's fitness would be to turn into a "transparent glass" as described above. However, there are good reasons to think that this is not the case.

Here is why: as I mentioned above, a specific pattern of light on the retina could be caused by different environmental configurations. Assume that one of these configurations, which happens not to be the most probable cause of that specific retinal pattern, has a biological significance for the organism. 
It is natural to think that the organism's vision should evolve to track the significant cause in question rather than the most probable one. Therefore, the most probable cause of a retinal pattern does not necessarily correspond to, evolutionarily speaking, its most significant cause (Orlandi, 2014, p. 70). Moreover, thanks to simulation methods using evolutionary games and genetic algorithms, we could simulate an organism's behavior in the natural environment, once with a visual system that is tuned to veridicality and once with a different visual system that is governed by fitness. The results are striking:

We tested this assumption [that vision tracks truth] using standard tools of evolutionary game theory. We found that truer perceptions need not be more fit: Natural selection can send perfectly, or partially, true perceptions to extinction when they compete with perceptions that use niche-specific interfaces which hide the truth in order to better represent utility. Fitness and access to truth are logically distinct properties. More truthful perceptions do not entail greater fitness. (Mark, Marion, \& Hoffman, 2010, p. 513; see also Hoffman \& Prakash, 2014; Singh \& Hoffman, 2013)

Thus, the very intuitive idea that the two visual systems will finally converge is not correct. This way of looking at the underdeterminacy problem suggests that visual experience is not a simple function tuned to veridicality; rather it is tuned to fitness which, in turn, depends not only on the way the environment is, but also on the organism, its current state, and its actions (Singh \& Hoffman, 2013, p. 176). Therefore, the resulting percepts in the two visual systems tuned respectively to fitness and veridicality need not and, as a matter fact, do not converge. As a result, what we see is, evolutionarily speaking, what has proved to serve our needs better in the past, rather than what is actually out there.

If this account of the perceptual system's operation is roughly correct, then a representational account of perceptual experience would naturally follow. Why? Well, a relation between the subject and the perceived objects and properties cannot determine the character of one's experience. As I understand it, according to the naïve realist, when the perceptual relation between the subject and her environment obtains, as Brewer puts it, "the core subjective character of perceptual experience is given simply by citing the physical object which is its mind-independent direct object" (2008, p. 171). ${ }^{12}$ However, according to the picture I presented above, the subjective character of experience need not be given by citing its direct physical objects. A normally operating perceptual system is not committed to and does not guarantee that how things perceptually appear is the same as how things really are. The visual system does not bypass the underdeterminacy of the retinal image by making inferences which reveal the state of distal objects. As Purves, Lotto, and Nundy put it:

what we perceive accords not with the features of the retinal stimulus or the properties of the underlying objects, but with what the same or similar stimuli have typically signified in both the experience of the species over the eons and the experience of the individuals over their lifetimes. (2002, p. 236)

In other words, the driving force behind the visual system is not coming from metaphysical direct realism; rather, the visual system is governed by the organism's biological needs. After all, if the organism could meet its biological needs without going through the labyrinth of having a veridical experience of the world which demands much more energy and time (Singh \& Hoffman, 2013), why would the organism bother to choose the latter?

Therefore, it is natural to assume that, in the absence of full access to the way the world is, the visual system puts the organism in a state that represents its environment as being a certain way. Otherwise how could we account for the transition from the highly underdetermined inputs that the visual system receives to the fine-grained visual experiences that we normally enjoy? Either the relation between the perceiver and the perceived object and properties fully determines the phenomenal character of the experience, or else the visual system represents the perceived scene in the absence of such a relation. ${ }^{13}$

\section{Conclusion}

Most representationalists have either assumed that perceptual experience has content or argued for perceptual content given unexamined assumptions about the nature of looks. So it should not be very surprising that Travis' 2004 paper brought about a great shock in the representationalist camp. However, I think the force of Travis' argument has been overstated, not because it does not wreak havoc on the 
representationalist camp, but because it affects only a specific sort of arguments for perceptual content, namely the arguments that take perceptual content to be determined by looks. As it happened, that was the main, maybe even the only, argument that representationalists had in their repertoire for perceptual content. However, perceptual experience could be representational for other reasons. Specifically, it could be representational due to the way the visual system works.

\section{Notes}

1. The WCT is silent on whether it is necessary or contingent that perceptual experience has content. I have discussed this issue elsewhere. See Shahmoradi (2015b).

2. For similar readings of Travis' argument, see Broggard (2015), Raleigh (2013), and Schellenberg (2014). In this section, I mainly rely on Brogaard's and Raleigh's interpretations of Travis. A different reading of the argument is presented by Byrne (2009).

3. "One idea would be that it is looks-indexing that makes such facts available to us; the representational content of an experience can be read off of the way, in it, things looked" Travis (2004, p. 69).

4. Also see Pautz (2009) for different formulations of this view. I assume that different sides of the debate accept that look statements report contents of looks (as mental states or events). Thus, moving between look statements and looks should be harmless.

5. It is worth noting that Travis is not alone in his criticism of Chisholm's tripartite analysis of appearance words. A more recent analysis of look statements is that of Martin (2010). Although Martin believes that his analysis is consistent with a representational theory of perception, he does agree with Travis at least in that "there are no true phenomenal look statements that concern things looking red or looking square" (2010, pp. 163, 223).

6. In order to see how perceptual psychology could account for error in this way, see Howe and Purves (2005) and Purves, Wojtach, and Lotto (2011). A more developed version of the cognitive account of error is that of Brewer (2008). I believe that Brewer's account has similar problems. For a discussion of Brewer's account, see Shahmoradi (2015a).

7. I believe that naive realism's resistance to the possibility of error in experience and their cognitive accounts of error spring from a Gibsonian approach to vision. As is well-known, Gibsonians do not accept that the visual system faces an underdeterminacy problem as I explained it in this paper. However, there seems to be little or no support for this approach in contemporary perceptual psychology. See Palmer (1999, pp. 54-55).

8. Note that Mark Johnston does not defend naïve realism. Here I am only using his formulation of positive disjunctivism.

9. Another negative proposal is that of Fish (2009). For a critique of Fish's views, see Siegel (2008).

10. Moreover, the arguments from how things appear in visual experience and the argument from accuracy conditions, even if successful, would not be very helpful in the dialectic between the representationalist and the naïve realist. As Pautz (2009) has argued, these arguments either deliver a trivially weak notion of content which is perfectly compatible with naive realism, or else convert some substantial debates, for instance the debate over which properties could be represented in experience, into debates about whether it is grammatical to say, for instance, "O looks pine tree."

11. Note that I do not take these (impersonal) assumptions to be representational.

12. Note that this is restatement of what we called "metaphysical direct realism." See also Campbell (2002, p. 116), Fish (2009, p. 6), and Travis (2004).

13. For a full discussion of this issue, see Shahmoradi (2015b). In this paper I have relied on two different approaches to the underdeterminacy of the retinal image: the Empirical Ranking Theory (Purves, Wojtach, \& Lotto, 2011) and a new form of Bayesianism, Computational Evolutionary Perception (Singh \& Hoffman, 2013). However, my arguments are also compatible with predictive coding models of perception. See Hohwy (2013).

\section{Acknowledgments}

Thanks to an anonymous reviewer for very helpful comments. Thanks also to Dale Purves, Brian McLaughlin, Cherie Braden, and David Braddon-Mitchell for discussions and/or comments. My special thanks, however, are reserved for Ben Bronner who patiently read and commented on multiple drafts of this paper.

\section{ORCID}

Ayoob Shahmoradi (D) http://orcid.org/0000-0003-3521-6760 


\section{References}

Brewer, B. (2008). How to account for illusion. In A. Haddock \& F. Macpherson (Eds.), Disjunctivism: Perception, action, knowledge (pp. 168-180). Oxford: Oxford University Press.

Brogaard, B. (2015). Perception without representation: On Travis's argument against the representational view of perception. Topoi.

Byrne, A. (2001). Intentionalism defended. Philosophical Review, 110, 199-240.

Byrne, A. (2009). Experience and content. Philosophical Quarterly, 59, 429-451.

Campbell, J. (2002). Reference and consciousness. Oxford: Oxford University Press.

Chalmers, D. (2004). The representational character of experience. In B. Leiter (Ed.), The future for philosophy (pp. 153-181). Oxford: Oxford University Press.

Chisholm, R. (1957). Perceiving: A philosophical study. Ithaca, NY: Cornell University Press.

Dretske, F. (1995). Naturalizing the mind. Cambridge, MA: MIT Press.

Fish, W. (2009). Perception, hallucination, and illusion. New York, NY: Oxford University Press.

Fish, W. (2010). Philosophy of perception: A contemporary introduction. Routledge.

Fish, W. (2010). Philosophy of perception: A contemporary introduction. Routledge.

Genone, J. (2014). Appearance and illusion. Mind, 123, 339-376.

Geisler, W., \& Diehl, R. (2003). A Bayesian approach to the evolution of perceptual and cognitive systems. Cognitive Science, 27, 379-402.

Gilchrist, A., Kossyfidis, C., Bonato, F., Agostini, T., Cataliotti, J., Li, X., \& Economu, E. (1999). An anchoring theory of lightness perception. Psychological Review, 106, 795-834.

Hoffman, D., \& Prakash, C. (2014). Objects of consciousness. Frontiers in Psychology, 5, 1-22.

Hohwy, J. (2013). The predictive mind. Oxford: Oxford University Press.

Horgan, T., \& Tienson, J. (2002). The intentionality of phenomenology and the phenomenology of intentionality. In D. Chalmers (Ed.), The philosophy of mind: Classical and contemporary readings (pp. 520-533). Oxford: Oxford University Press.

Howe, C. Q., \& Purves, D. (2005). The Müller-Lyer illusion explained by the statistics of image-source relationships. Proceedings of National Academy of Sciences, 102, 1234-1239.

Howe, C. Q., Lotto, R. B., \& Purves, D. (2006). Comparison of Bayesian and empirical ranking approaches to visual perception. Journal of Theoretical Biology, 241, 866-875.

Johnston, M. (2004). The obscure object of hallucination. Philosophical Studies, 120, 113-183.

Kleffner, D. A., \& Ramachandran, V. S. (1992). On the perception of shape from shading. Perception and Psychophysics, $52,18-36$.

Mark, J. T., Marion, B. B., \& Hoffman, D. D. (2010). Natural selection and veridical perceptions. Journal of Theoretical Biology, 266, 504-515.

Martin, M. G. F. (2004). The limits of self-awareness. Philosophical Studies, 120, 37-89.

Martin, M. G. F. (2006). On being alienated. In T. S. Gendler \& J. Hawthorne (Eds.), Perceptual experience (pp. 354-410). Oxford: Oxford University Press.

Martin, M. G. F. (2010). What's in a look? In B. Nanay (Ed.), Perceiving the world (pp. 160-225). Oxford: Oxford University Press.

Orlandi, N. (2014). The innocent eye: Why vision is not a cognitive process. Oxford: Oxford University Press.

Palmer, S. (1999). Vision science: Photons to phenomenology. Cambridge, MA: MIT Press.

Pautz, A. (2009). What are the contents of experiences? Philosophical Quarterly, 59, 483-507.

Purves, D., Lotto, R. B., \& Nundy, S. (2002). Why we see what we do. American Scientist, 90, 236-243.

Purves, D., Wojtach, A., \& Lotto, R. B. (2011). Understanding vision in wholly empirical terms. Proceedings of the National Academy of Sciences, 108, 15588-15595.

Pylyshyn, Z. (1999). Is vision continuous with cognition? The case for cognitive impenetrability of visual perception. Behavioral and Brain Sciences, 22, 341-423.

Raleigh, T. (2013). Phenomenology without representation. European Journal of Philosophy, 23, 1209-1237.

Schellenberg, S. (2011). Perceptual content defended. Nous, 45, 714-50.

Schellenberg, S. (2014). The relational and representational character of perceptual experience. In B. Brogaard (Ed.), Does perception have content? (pp. 199-219). Oxford: Oxford University Press.

Shahmoradi, A. (2015a). Naive realism and error. Unpublished manuscript.

Shahmoradi, A. (2015b). Terrestrial perception vs. edenic perception. Unpublished manuscript.

Siegel, S. (2004). Indiscriminability and the phenomenal. Philosophical Studies, 120, 90-112.

Siegel, S. (2008). The epistemic conception of hallucination. In A. Haddock \& F. Macpherson (Eds.), Disjunctivism: Perception, action, knowledge (pp. 205-224). Oxford: Oxford University Press.

Siegel, S. (2010). Do experiences have contents? In B. Nanay (Ed.), Perceiving the world (pp. 333-368). Oxford: Oxford University Press.

Siewert, C. (1999). Significance of consciousness. Princeton: Princeton University Press. 
Singh, M., \& Hoffman, D. (2013). Natural selection and shape perception. In S. Dickinson \& Z. Pizlo (Eds.), Shape perception in human and computer vision: An interdisciplinary perspective (pp. 171-185). London: Springer.

Snowden, R., Thompson, P., \& Troscianko, T. (2012). Basic vision: An introduction to visual perception (Revised ed.). Oxford: Oxford University Press.

Sturgeon, S. (2006). Reflective disjunctivism. Proceedings of the Aristotelian Society, 80, 185-216.

Travis, C. (2004). The silence of the senses. Mind, 113, 57-94.

Tye, M. (1995). Ten problems of consciousness: A representational theory of the phenomenal mind. Cambridge, MA: MIT Press.

Tye, M. (2000). Consciousness, color, and content. Cambridge, MA: MIT Press. 